\title{
Álbum de Figurinhas Online como ferramenta de Educação Ambiental em Museu de Biologia*
}

\section{Online Cards Album as a tool for Environmental Education in a Biology Museum}

\author{
MÔNICA SALAZAR-SOUZA \\ Universidade Federal Fluminense \\ EVERTON MESSIAS SANTOS SENA \\ Instituto Federal do Espírito Santo
}

\author{
ARLINDO SERPA FILHO \\ Instituto Nacional da Mata Atlântica
}

\begin{abstract}
Resumo: A Mata Atlântica é considerada um dos 25 hotspots mundiais de biodiversidade, abrigando atualmente em suas áreas remanescentes 598 espécies ameaçadas. Para contribuir no conhecimento de algumas dessas espécies e no despertar para a conservação, propomos o álbum 'Por dentro da Mata Atlântica', como projeto do Programa de Capacitação Institucional da Difusão Científica do Instituto Nacional da Mata Atlântica. Após teste de uso e avaliação via questionário, observamos que $66,7 \%$ dos usuários foram alunos. A aparência e usabilidade foram aprovadas $81,8 \%$ e $63,6 \%$ dos usuários, respectivamente. Apenas 9,1\% dos usuários revelaram não entender o conteúdo textual. As perguntas vinculadas às imagens foram compreendidas por $54,5 \%$ dos usuários. Foi considerada ferramenta educativa pelos professores e, 95,5\% dos alunos gostariam de utilizar o jogo no ambiente escolar. Do total de usuários, 66,7\% afirmaram que o álbum Ihes acrescentou conhecimento, revelando seu potencial como ferramenta de educação ambiental e difusão científica.
\end{abstract}

Palavras-chave: Jogo Educativo. Ludicidade. Preservação. Divulgação Científica.

\begin{abstract}
The Atlantic Forest is considered one of the 25 biodiversity hotspots worldwide, currently housing 598 endangered species in its remaining areas. To contribute to the knowledge of some of these species and in awakening to conservation, we propose the album 'Por dentro da Mata Atlântica', as a project of the Institutional Capacity Building Program of the Scientific Diffusion of the National Institute of the Atlantic Forest. After use test and evaluation via questionnaire, we observed that $66.7 \%$ of the users were students. The appearance and usability were approved $81.8 \%$ and $63.6 \%$ of users, respectively. Only $9.1 \%$ of users revealed that they did not understand textual content. The questions linked to the images were understood by $54.5 \%$ of users. It was considered an educational tool by the teachers and, $95.5 \%$ of the students would like to use the game in the school environment. Of the total users, $66.7 \%$ said that the album added them knowledge, revealing their potential as a tool for environmental education and scientific diffusion.
\end{abstract}

Keywords: Educational Game. Playfulness. Preservation. Scientific Divulgation. ferramenta de Éducação' Ambiental em Museu de Biologia, Porto Alegre, v. 22, n. 1, p. 95-110, jan./jul. 2019.

* Artigo elaborado a partir do Projeto de Pesquisa Fortalecimento Científico do Instituto Nacional da Mata Atlântica - $2^{\circ}$ biênio, com o apoio do CNPq através do edital do Programa de Capacitação Institucional/PCI do MCTI 2015-2018. 


\section{Introdução}

Considerada a segunda maior floresta pluvial tropical do continente americano e um dos 25 hotspots mundiais de biodiversidade, a Mata Atlântica, em sua formação original, estendia-se por mais de 1,5 milhões de $\mathrm{km}^{2}$, com 92\% desta área no Brasil, alcançando ainda, o leste do Paraguai e nordeste da Argentina na porção sul (TABARELLI et al., 2005).

Segundo o relatório técnico apresentado no Atlas dos Remanescentes Florestais da Mata Atlântica 2015/2016, elaborado pela Fundação SOS Mata Atlântica em parceria com o Instituto Nacional de Pesquisas Espaciais (INPE), a Mata Atlântica ocupa atualmente dezessete estados brasileiros inseridos em quatro regiões: Nordeste (Bahia, Sergipe, Alagoas, Piauí, Pernambuco, Paraíba, Rio Grande do Norte e Ceará), Centro-Oeste (Mato Grosso do Sul e Goiás), Sudeste (São Paulo, Rio de Janeiro, Espírito Santo, e Minas Gerais) e Sul (Rio Grande do Sul, Santa Catarina, e Paraná).

De acordo com a última lista da fauna brasileira ameaçada de extinção elaborada pelo Instituto Chico Mendes de Conservação da Biodiversidade/ICMBIO entre os anos de 2009 e 2014, a Mata Atlântica abriga 598 espécies ameaçadas e 428 espécies endêmicas ameaçadas (ICMBIO, 2016; FUNDAÇÃO SOS Mata Atlântica; INPE, 2017).

A acentuada devastação da Mata Atlântica reflete diretamente nas relações entre as espécies endêmicas de flora e associações de interdependência, tendo como consequência o aumento da proporção de espécies ameaçadas de extinção, alertando para o risco de muitas espécies estarem ou já terem sido extintas, antes que se possam ser conhecidas (FRANKE et al., 2005).

Segundo Nascimento (2017), a conservação da biodiversidade está interligada à conservação dos recursos naturais, e ambos estão diretamente relacionados ao conhecimento dos locais e suas comunidades por meio da observação ou práticas que promovam o detalhamento da fauna e flora, para que sejam aplicadas estratégias adequadas que contribuirão na manutenção e desenvolvimento dessas comunidades.

A consciência sobre a conservação está intimamente ligada ao conhecimento. Para isso, é essencial uma educação ambiental contínua, capaz de despertar em crianças, adolescentes e adultos, uma consciência ecológica crítica, voltada para a valorização, preservação do meio ambiente e desenvolvimento sustentável, para que se possa desfrutar do meio ambiente sem extinguir seus recursos (TOALDO; MEYNE, 2013).

Tão importante quanto serem conhecidas pela ciência, é a popularização dessas espécies. Nesse sentido, os jogos digitais educativos se destacam como potenciais ferramentas tecnológicas. Os jogos digitais assumiram papel de destaque na cultura contemporânea, impactando consideravelmente a vida dos jogadores, seduzidos pelo desafio e fantasia proposta (SAVI, 2008). Utilizado na difusão científica e ensino-aprendizagem, o jogo digital é capaz de transmitir a informação de forma atrativa e inovadora, possibilitando a quem recebe o aprendizado de forma mais ativa, dinâmica e motivadora (GROS, 2007).

Desta forma, propomos o desenvolvimento e utilização de jogo educativo, no formato álbum de figurinhas online, 'Por dentro da Mata Atlântica' para o Instituto Nacional da Mata Atlântica (INMA), localizado em Santa Teresa, ES, como ferramenta de popularização de algumas espécies da fauna e flora da Mata Atlântica, classificadas em estado de conservação.

Espera-se que o processo interativo e lúdico durante o processo de preenchimento do álbum contribua para o conhecimento das diferenças morfológicas e biológicas das espécies apresentadas, para a sensibilização quanto à preservação das espécies ameaçadas, e agregação de novos saberes através de um aprendizado espontâneo e prazeroso. 


\section{METODOLOGIA}

O álbum de figurinhas foi elaborado utilizando-se textos e imagens, abordando os assuntos: abrangência do bioma, características das formações florestais, espécies animais encontradas nas regiões de abrangência, situações de ameaça e estado de conservação de fauna e flora.

As espécies animais e vegetais foram selecionadas aleatoriamente, tendo como critérios, a presença em pelo menos uma das regiões abrangidas pelo bioma e estarem classificadas como: Criticamente em Perigo - CR, Em Perigo - EN ou Vulnerável - VU, segundo as listas de espécies ameaçadas do Livro Vermelho da Fauna Brasileira Ameaçada de Extinção (CHIARELLO et al., 2008; HADDAD, 2008; MACHADO et al., 2008; MARTINS; MOLINA, 2008; ROSA; LIMA, 2008; SILVEIRA; STRAUBE, 2008), da Fundação Biodiversitas, online e, da Lista Vermelha da Flora do Centro Nacional de Conservação da Flora/CNCFLORA, online (Tabela 1).

Simultaneamente à pesquisa textual foram realizadas pesquisas no ambiente virtual Google Imagens ${ }^{\odot}$ para obtenção de fotografias das espécies previamente selecionadas, preenchendo os seguintes critérios: qualidade acima de $300 \mathrm{dpi}$, nítida visualização do espécime, correta identificação do nome científico da espécie pelo autor da imagem, citação de autoria e ausência de proibição de utilização de imagem.

Ao término da seleção, as imagens foram inseridas em uma base de identificação desenvolvida no software Adobe ${ }^{\circledR}$ Photoshop $\mathrm{CS}^{\circledR}{ }^{\circledR}$ sendo transformadas em figurinhas medindo $7,0 \mathrm{~cm} \times 5,0 \mathrm{~cm}$ (horizontal) e 5,0 cm X7,0 cm (vertical), contendo: a imagem do animal, 0 nome do livro ilustrado, o nome popular da espécie, o estado de conservação por extenso com a respectiva sigla e cor associada seguindo o mesmo padrão utilizado nas listas de espécies ameaçadas do Livro Vermelho da Fauna Brasileira Ameaçada de Extinção (CHIARELLO et al., 2008; HADDAD, 2008; MACHADO et al., 2008; MARTINS; MOLINA, 2008; ROSA; LIMA, 2008; SILVEIRA; STRAUBE, 2008) e da Lista Vermelha do CNCFLORA (Figura 1A; B). As figurinhas inseridas na versão impressa receberam acréscimo de numeração sequencial de acordo com o seu posicionamento no interior do livro (Figura 1C; D).

\section{1 Álbum de Figurinhas Online}

A primeira etapa de construção foi desenvolvida na ferramenta Bloco de Notas do Windows ${ }^{\circledR}$, para estruturação dos campos de perguntas e opções de respostas (radio), codificação do comando para movimentação das figurinhas em caso de erro ou acerto, e codificação da sobreposição de tela com apresentação da descrição biológica e ecológica, ativada através de um link, nominado "Saiba mais".

A segunda etapa de construção foi desenvolvida no software SerifWebPlus $X 8^{\circledR}$, para caracterização da aparência (layout), dinâmica e acessibilidade das páginas, e estruturação geral do álbum. Nas duas etapas de desenvolvimento foram utilizadas as linguagens de programação: Hyper Text Markup Language (HTML) com a função de determinar o conteúdo das páginas, Java Script para delinear o comportamento das páginas, CSS para caracterizar o layout das páginas.

Na concepção de cada parte do álbum online, se trabalhou da seguinte maneira:

Página inicial. Disponibiliza três botões que possibilitam o acesso a três páginas independentes (Figura 2). Os objetivos, modo de preenchimento e movimentação no interior do álbum foram reunidos na página "regras". As informações textuais apresentando as formações florestais das regiões abrangidas pela Mata Atlântica foram agrupadas na página "entrar". Três espécies florestais são apresentadas visualmente através de recurso slide, contendo rótulo com breve descrição: nome científico, nome popular, distribuição atual, ameaças, localização e estado de conservação. Nessa página foi disponibilizado um link de acesso à primeira página de preenchimento do álbum. As informações de autorias das imagens e desenvolvedores do álbum foram reunidas na página "créditos". 
Páginas de preenchimento. Cada página de preenchimento representa uma das quatro regiões de abrangência atual da Mata Atlântica. Elas foram agrupadas iniciando pela menor, a região Centro-Oeste. O preenchimento de cada figurinha do álbum está condicionado ao acerto de perguntas relacionadas às espécies a serem visualmente conhecidas. Cada página foi elaborada contendo grupos de três a seis perguntas, totalizando 21 perguntas/ 21 figurinhas, com apenas uma opção de resposta válida entre três opções disponíveis.

Adicional às imagens foi agregado o link "Saiba mais" contendo informações adicionais de determinada espécie a respeito da biologia, alimentação, localização, ameaças e estado de conservação no ambiente (Figura 3). Um link para download de uma versão impressa no formato Portable Document Format (PDF) foi disponibilizado na página de finalização do jogo, sequencial à página da região Nordeste, última página de preenchimento.

\section{2 Álbum de Figurinhas Impresso}

A versão impressa desenvolvida em PDF foi diagramada com auxílio do software Adobe ${ }^{\circledR}$

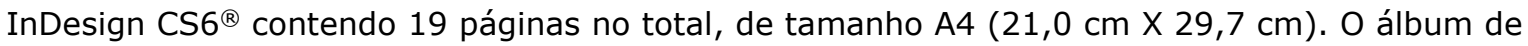
figurinhas foi dividido internamente em páginas de apresentação, regiões, preenchimento e figurinhas.

As páginas de regiões foram entrepostas às páginas de preenchimento, contendo a caracterização das formações florestais existentes nas regiões de abrangência da Mata Atlântica. As páginas de preenchimento reúnem informações biológicas, localização, ameaças e estado de conservação no ambiente de 27 espécies de animais/figurinhas, posicionadas ao lado do texto. As figurinhas foram disponibilizadas para recorte nas páginas finais do álbum (Tabela 1) (Figura 4).

\subsection{Fase de Teste}

A versão online foi desenvolvida para ser acessada pelo usuário através de um link. No entanto, os testes foram realizados em uma versão off-line. Um computador foi instalado em uma das salas de exposição do Pavilhão de Botânica Florestal Dr. Graciano dos Santos Neves, do Museu de Biologia Professor Mello Leitão, integrando a exposição temporária de jogos pedagógicos, desenvolvidos pelo Setor de Difusão Científica.

Após serem apresentados ao álbum de figurinhas, os visitantes foram convidados a participar da brincadeira e ao término parcial ou total, os mesmos puderam participar da avaliação através de questionário de pesquisa qualitativa, contendo dois blocos de questões, divididos em perguntas múltiplas fechadas binárias e escalonadas e discursivas, com 16 questões no total, elaborados segundo a metodologia proposta por Sonia Vieira (2009).

O primeiro bloco buscou traçar o perfil do visitante através das perguntas: Você é (aluno, professor, visitante espontâneo)?, idade, Estado/UF, a frequência de visitação a museus de Ciências/História Natural e a frequência de visitação no MBML/INMA.

O segundo bloco avaliou a aparência geral do álbum e a adequação das imagens, a facilidade de movimentação pelas páginas, acesso e compreensão dos conteúdos, incluindo as perguntas e respostas utilizadas na dinâmica de preenchimento do álbum, a utilização do álbum como ferramenta pedagógica (apenas professores) e no cotidiano escolar (apenas alunos), eventuais dificuldades no processo do preenchimento, o acréscimo de conhecimento, finalizando a avaliação com espaço para críticas e sugestões.

Como complemento da pesquisa qualitativa realizada através do questionário, foi utilizado como recurso técnico de avaliação da ferramenta, a observação dos participantes durante o preenchimento do álbum. Para caracterização da amostra, as variáveis foram apresentadas como proporções. 


\section{RESULTADOS E DISCUSSÃO}

O Museu de Biologia Professor Mello Leitão (MBML), localizado em Santa Teresa, Espírito

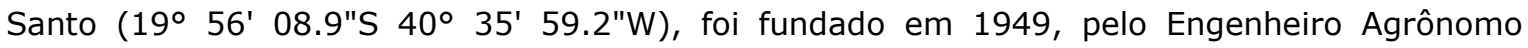
Augusto Ruschi. O acervo inicial era composto de exemplares de orquídeas e beija-flores, coletados e identificados por Ruschi na Mata Atlântica do Espírito Santo. Ao longo do tempo, Ruschi e pesquisadores colaboradores, enriqueceram os acervos botânico e zoológico, que contabiliza atualmente, mais de 42 mil amostras de plantas, conservadas em exsicatas e meio líquido, e mais de 21 mil exemplares, incluindo: aves, mamíferos, anfíbios, répteis e peixes, conservados em meio seco e líquido.

As coleções biológicas são restritas à pesquisa científica, mas alguns exemplares botânicos e zoológicos compõem a exposição biológica permanente, aberta à visitação pública espontânea ou mediada. As visitas mediadas são previamente agendadas, disponibilizadas para grupos. Os visitantes são apresentados à história de fundação do museu e de seu fundador, sendo conduzidos posteriormente, até os pavilhões de exposição, onde podem conhecer os animais vertebrados taxidermizados ou conservados em meio líquido, sementes e folhas de exemplares botânicos, existentes na Mata Atlântica. Durante a visita guiada são incorporadas atividades relacionadas à educação ambiental.

Por intermédio da Lei 12.954, sancionada em 05 de fevereiro de 2014, o MBML foi incorporado ao Ministério da Ciência, Tecnologia, Inovações e Comunicações (MCTIC), dando origem ao Instituto Nacional da Mata Atlântica. A mudança estrutural contribuiu para a intensificação de atividades relacionadas à popularização da ciência na localidade. Atualmente, o INMA é considerado um dos polos de educação ambiental no Espírito Santo, recebendo cerca de 80 mil visitantes por ano. São frequentes as visitas de alunos e professores oriundos de municípios vizinhos à Santa Teresa (Santa Maria de Jetibá, Santa Leopoldina, São Roque do Canaã, Colatina, Itarana e Itaguaçu), além de visitantes brasileiros e estrangeiros em razão do perfil turístico da cidade, pesquisadores e estudantes de cursos de graduação e pós-graduação do Brasil e exterior.

Os jogos didáticos estão entre os recursos utilizados na educação ambiental e difusão científica direcionada aos visitantes do museu. O álbum de figurinhas 'Por dentro da Mata Atlântica' é a primeira ferramenta virtual desenvolvida para essa finalidade.

Durante o período de teste, ocorrido em dezembro de 2017, o MBML/INMA recebeu cerca 222 visitantes. Deste total, 33 visitantes se dispuseram a testar e avaliar espontaneamente 0 álbum de figurinhas virtual (Figura 5). A partir dos critérios descritos acima, expomos os resultados.

As respostas relacionadas ao primeiro bloco de perguntas revelaram que a maioria dos participantes foram alunos, com idades entre 8 a 17 anos $(66,7 \% ; n=17)$, e em menor frequência, professores com idades entre 33 a 37 anos $(9,1 \% ; n=3)$ (Tabela 2). Quando questionados sobre o hábito de visitação a museus, $51,5 \%(n=17)$ dos visitantes afirmaram já terem visitado Museus de Ciências ou História Natural anteriormente. O mesmo percentual de visitantes afirmaram não terem visitado o MBML/INMA anteriormente, na maioria das vezes, alunos (45,5\%; $n=15$ ) (Tabela 2 ). Esses valores observados podem estar relacionados com a origem dos visitantes durante o período de teste. A maioria dos visitantes durante o período de teste é oriunda de localidades vizinhas ao município de Santa Teresa/ ES (Figura 6).

A respeito do que esperavam encontrar durante a visitação no MBML/INMA, animais e exposições foram as opções mais citadas com $81,8 \%$ e $39,5 \%$ respectivamente, enquanto jogos e brincadeiras foram as opções menos citadas, ambos com 9,0\% (Tabela 3).

A pouca ou nenhuma expectativa dos visitantes quanto à presença de jogos e brincadeiras no museu, pode estar relacionada com a visão retrograda a respeito da finalidade dos museus, comumente associada a um local utilizado para salvaguardar exemplares de fauna, flora ou relíquias históricas, onde o contato físico com os artefatos é proibido, alimentando a crença de 
que a visita ao museu é uma obrigação cultural tediosa (BERTOLETTI-DE-MARCHI; SILVA, 2004).

Nesse sentido, a introdução de atividades lúdicas durante a visitação contribui significativamente para quebra de mitos acerca de museus. As brincadeiras e jogos quando utilizados em museus, converte a experimentação da visitação. Uma experimentação que era dependente da percepção e absorção do visitante modifica-se para ativa e estimulante, pelo fato de os jogos representarem movimento e desafio, permitindo que o visitante lide com determinada situação compreendendo seu significado (SANTANA; NOGUEIRA-FERREIRA, 2009; ANGÉLICO, 2010).

As respostas relacionadas ao segundo bloco de perguntas, que avaliou especificamente o álbum de figurinhas, revelaram que $81,8 \%$ dos jogadores consideraram layout do álbum virtual atraente (Q1). Sobre a usabilidade, no que diz respeito à facilidade no acesso os conteúdos e preenchimento do álbum virtual foram atestadas por $63,6 \%$ dos jogadores (Q2). Apenas $9,1 \%$ expressaram terem tido dificuldade no entendimento do conteúdo textual geral (Q3). O tamanho das imagens foi considerado adequado por 75,8\% dos jogadores (Q4). Quanto ao conteúdo das perguntas e respostas, elas foram facilmente compreendidas $54,5 \%$ dos jogadores (Q5).

Em pergunta especifica para os professores, todos consideraram a possibilidade de utilização do álbum como ferramenta de ensino-aprendizagem (Q6). Em pergunta especifica para os alunos, 95,5\% revelaram que gostariam de utilizar o jogo no ambiente escolar (Q7). Do total de visitantes que utilizaram o álbum, 69,7\% o preencheram por completo (Q8), e $66,7 \%$ afirmaram que o álbum Ihes acrescentou conhecimento a respeito do bioma Mata Atlântica (Q9) (Tabela 4).

Embora o álbum não possua marcadores de pontuação e cronometragem de tempo de preenchimento, foi possível avaliar por observação, que alguns erros tiveram relação com o desconhecimento de algumas espécies, e que a qualidade da leitura e interpretação de algumas perguntas, impactaram no tempo de preenchimento. Essa dificuldade foi observada com maior frequência em jogadores com idades entre 8 a 11 anos, que algumas vezes, necessitaram de auxílio de leitura por parte de colegas ou monitores de visitação do MBML/INMA.

Em relação à baixa aderência dos professores na utilização do álbum de figurinhas online, observamos ter sido influenciada pela postura do professor durante a visitação. Na maioria das vezes, os professores se limitaram a observar os alunos à distância, por vezes, mantendo-se sentados, enquanto estes manuseavam o álbum online e outros jogos disponíveis no espaço lúdico.

É possível que esse comportamento esteja relacionado à dificuldade de entendimento sobre como ocorre à educação nos museus, de que ela depende da percepção do professor quanto ao potencial educacional dos objetos musealizados. Ou, a falta de conhecimento prévio do conteúdo expositivo, tendo como resultando o não aproveitando da visitação por desconhecimento do assunto, diminuindo ou anulando a possibilidade de utilizar a ludicidade dos jogos ou brincadeiras, como neste caso, em reforço aos conteúdos de ciências e biologia, relacionados ao Meio Ambiente (ALMEIDA, 1997; BRASIL, 1997; CURY, 2013).

O potencial lúdico e educativo foi observado em depoimentos espontâneos em elogios e críticas.

"Gostei muito, e gostaria que esse jogo estivesse disponível para a escola, pois ajudaria muito na didática e no ensino." (Professora, 33 anos, São Roque, ES).

"Eu gostei muito desse jogo porque ele ensina sobre os animais onde ele vive qual é a espécie. Ele é bastante legal e bastante interessante pra nós." (Aluno, 11 anos, Aracruz, ES).

"Gostei muito porque eu pude aprender sobre os animais e sobre a Mata Atlântica." (Aluno, 10 anos). 
Segundo Grübele Bez (2006), os jogos possibilitam a construção do aprendizado, despertando a curiosidade, levando a procura de novos conhecimentos. Nesse sentido, as características de questionário e desafio, que movimentam a construção do álbum de figurinhas 'Por dentro da Mata Atlântica', possibilitam uma atividade interativa com potencial para estimular a capacidade criativa e lógica, mas como qualquer outro jogo educativo, sua eficiência na utilização como ferramenta de ensino-aprendizagem estará relacionada à atuação do professor como mediador na construção do conhecimento, entendendo as dificuldades e potencialidades de seus alunos, principalmente nos momentos de erro ou fracasso na conclusão (RIBEIRO, 2014; PAULA; VALENTE, 2016).

\title{
4 CONSIDERAÇÕES FINAIS
}

Os jogos de construção trazem à luz determinado assunto desconhecido, fazendo com que, através da sua prática o jogador sinta a necessidade de buscar novos conhecimentos para resolver as questões propostas pelo jogo (LARA, 2004).

No que tange à proposta conhecer para preservar, os resultados apontaram que a atmosfera lúdica contribuiu significativamente no envolvimento do jogador/colecionador com o conteúdo exposto. Envolvimento observado em cada manifestação de erro e acerto, de surpresa na descoberta dos animais apresentados e de informações a respeito deles que para muitos eram desconhecidas, inclusive, a respeito de animais que habitam em sua região.

\begin{abstract}
As possibilidades de se arriscar e errar no jogo permite que o estudante desenvolva sua consciência a respeito do que sabe e do que precisa aprender sobre o conteúdo envolvido no jogo [...] As marcas emocionais que o jogo pode imprimir à aprendizagem no ensino de ciências só têm sentido se se superar a dicotomia entre pensar e sentir, entre afeto e cognição. Isso significa que, para que as impressões emocionais timbradas no estudante sejam efetivamente relevantes, é preciso que o conteúdo presente no jogo ajude o estudante a entender a realidade. (MESSEDER NETO; MORADILLO, 2017).
\end{abstract}

Considerando sua avaliação positiva, cremos em seu potencial como ferramenta de popularização e sensibilização, e em seu potencial como colaborador da formação e/ou desenvolvimento cognitivo, do pensamento critico e reflexivo a respeito das vulnerabilidades do ambiente no qual estamos inseridos. 


\section{Figuras}

Figura 1 - (A) Base de identificação; (B) Figurinha do álbum virtual no formato horizontal. Original no tamanho $7,0 \mathrm{~cm} X$ $5,0 \mathrm{~cm}$; (C) Figurinha do álbum impresso no formato horizontal. Original no tamanho 7,0 cm X 5,0 cm; (D) Espaço reservado para inserção da figurinha no álbum impresso.
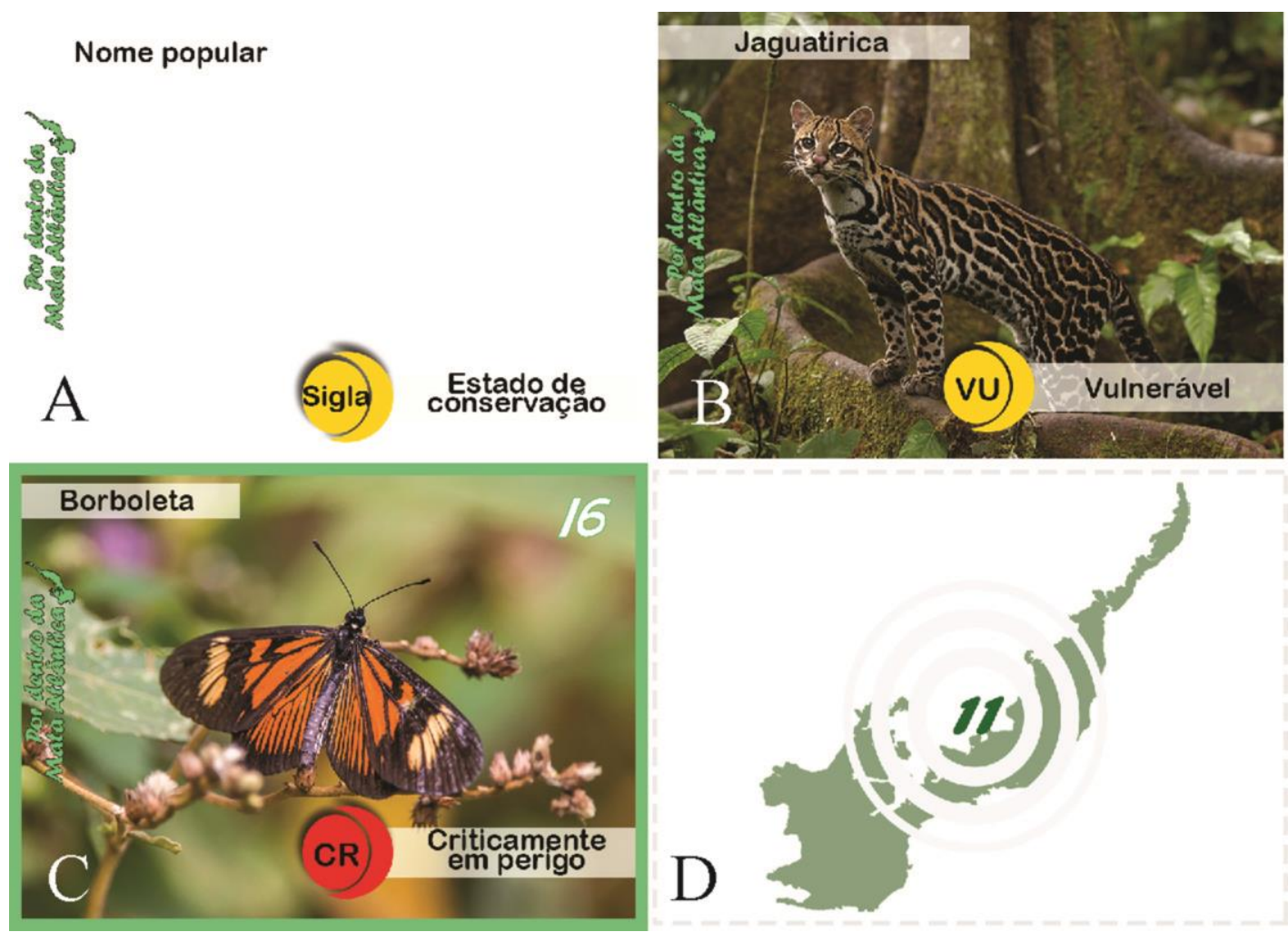

Fonte: Autor.

Figura 2 - Página inicial do álbum de figurinhas online Por dentro da Mata At/ântica com disposição dos botões: regras, entrar e créditos. 


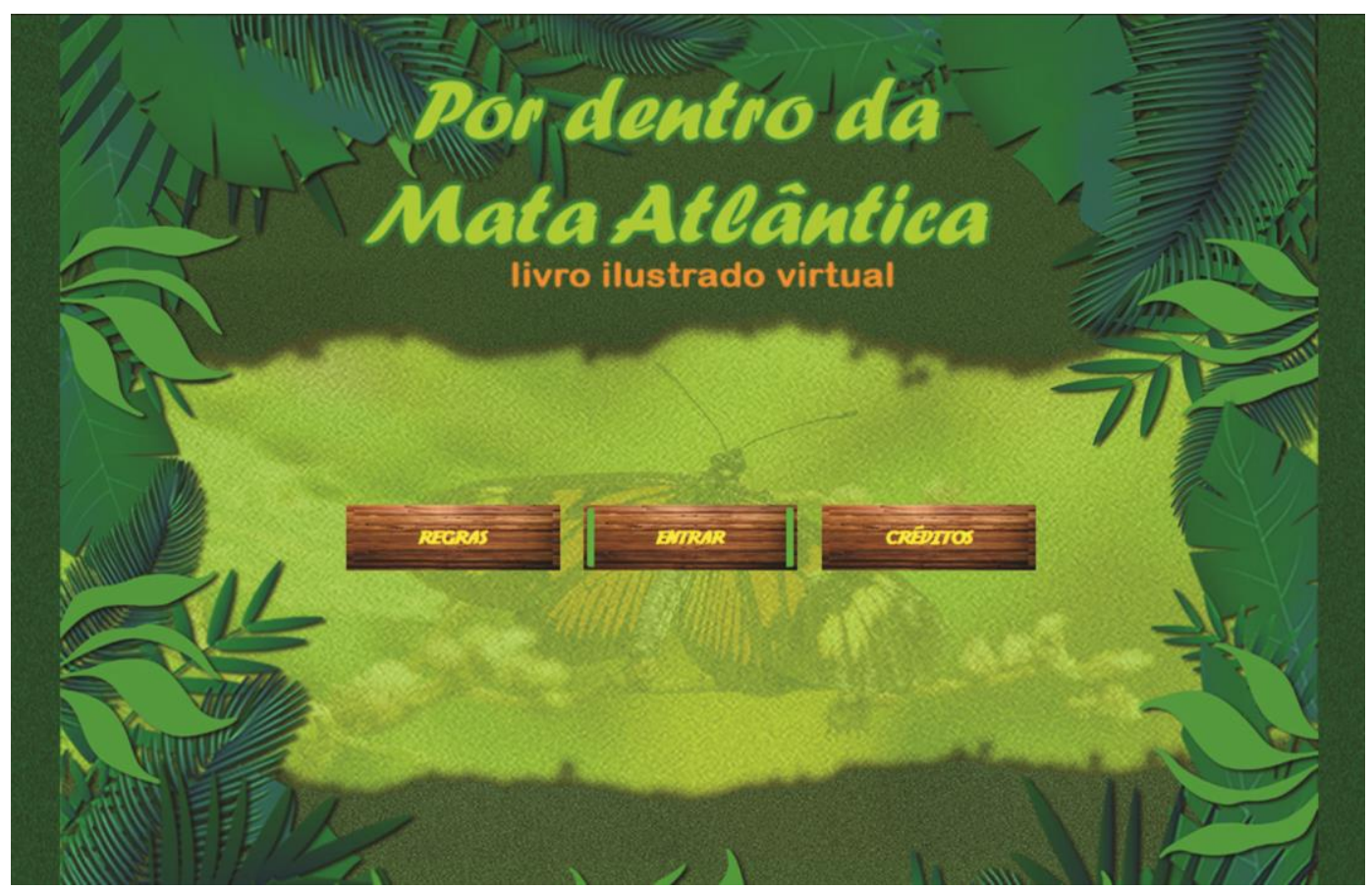

Fonte: Autor.

Figura 3 - Página de preenchimento da região Sul na versão online do álbum Por dentro da Mata Atlântica. Descrição da região e objetivos (A); botões de transição entre páginas (B); tela de conteúdo disponível no link Saiba mais (C); página com questões respondidas (D).

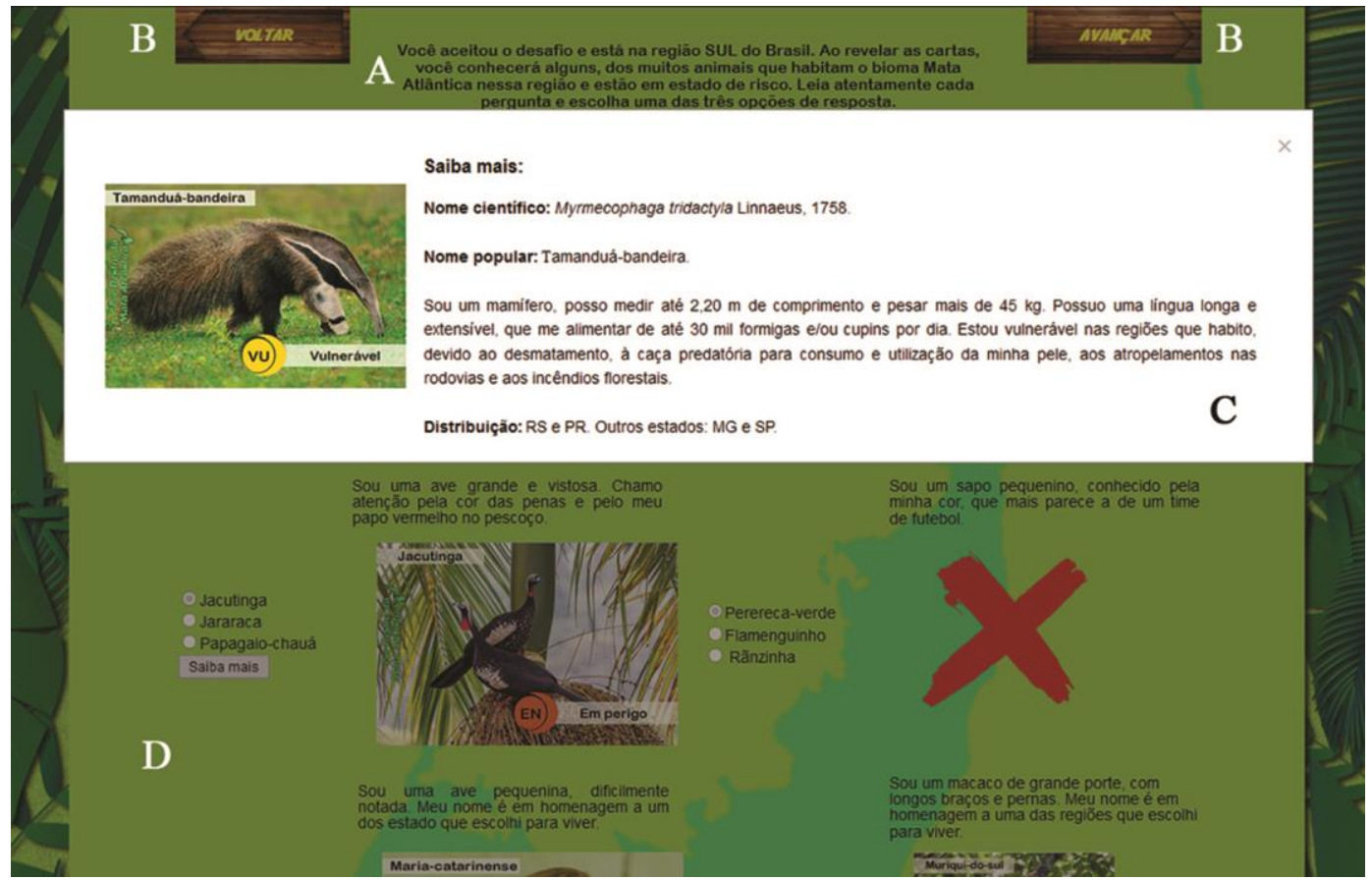

Fonte: Autor.

Figura 4 - Capa da versão impressa do álbum Por dentro da Mata Atlântica (A); página de apresentação da região Sul com a espécie Araucaria angustifolia (Araucária) ao fundo e aba com descrição da composição florestal da região (B); página de preenchimento (C). 

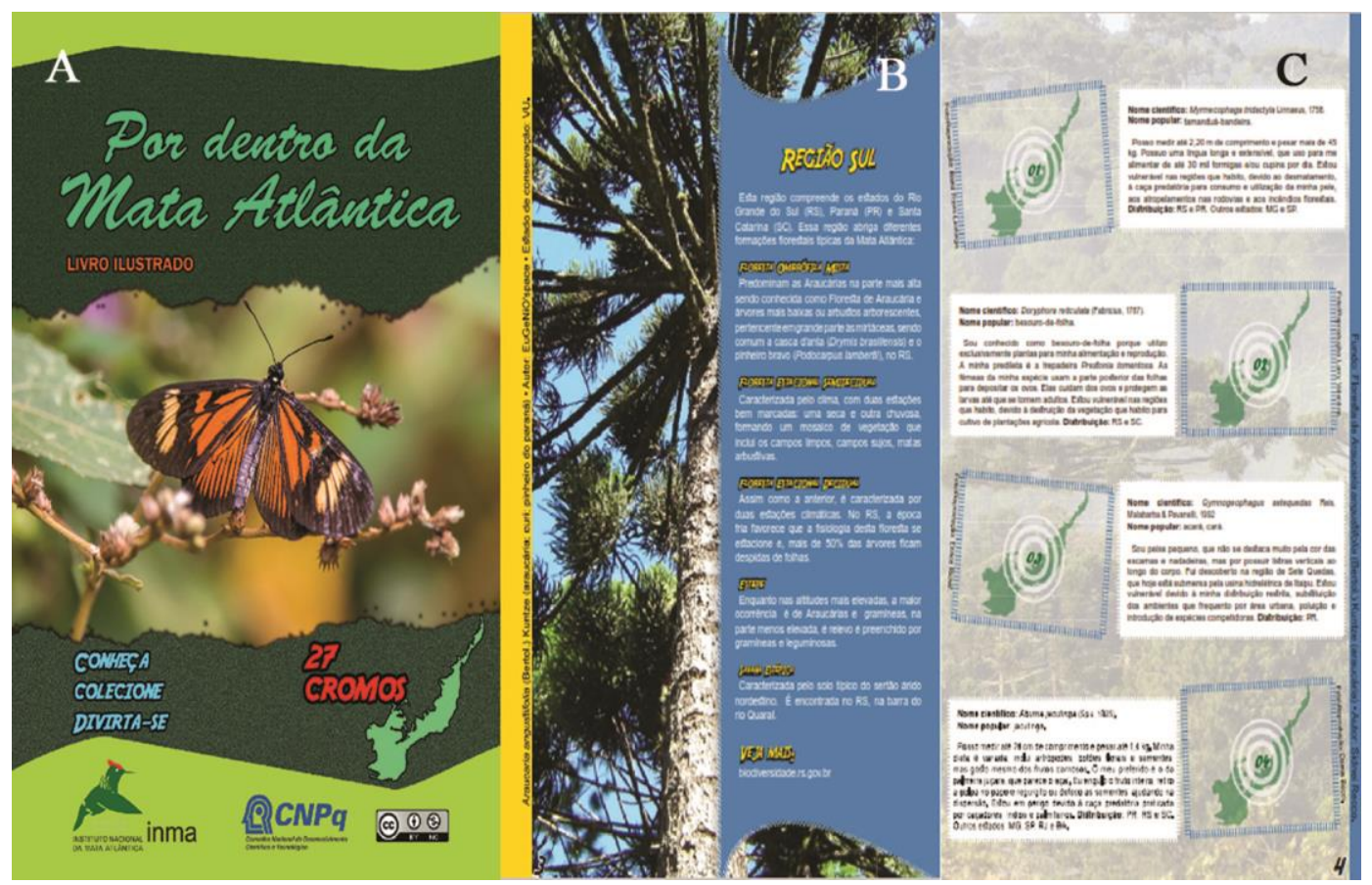

Fonte: Autor.

Figura 5 - Apresentação a publico e teste de utilização do álbum online (off-line) realizado por alunos em visitação ao Museu de Biologia Professor Mello Leitão.

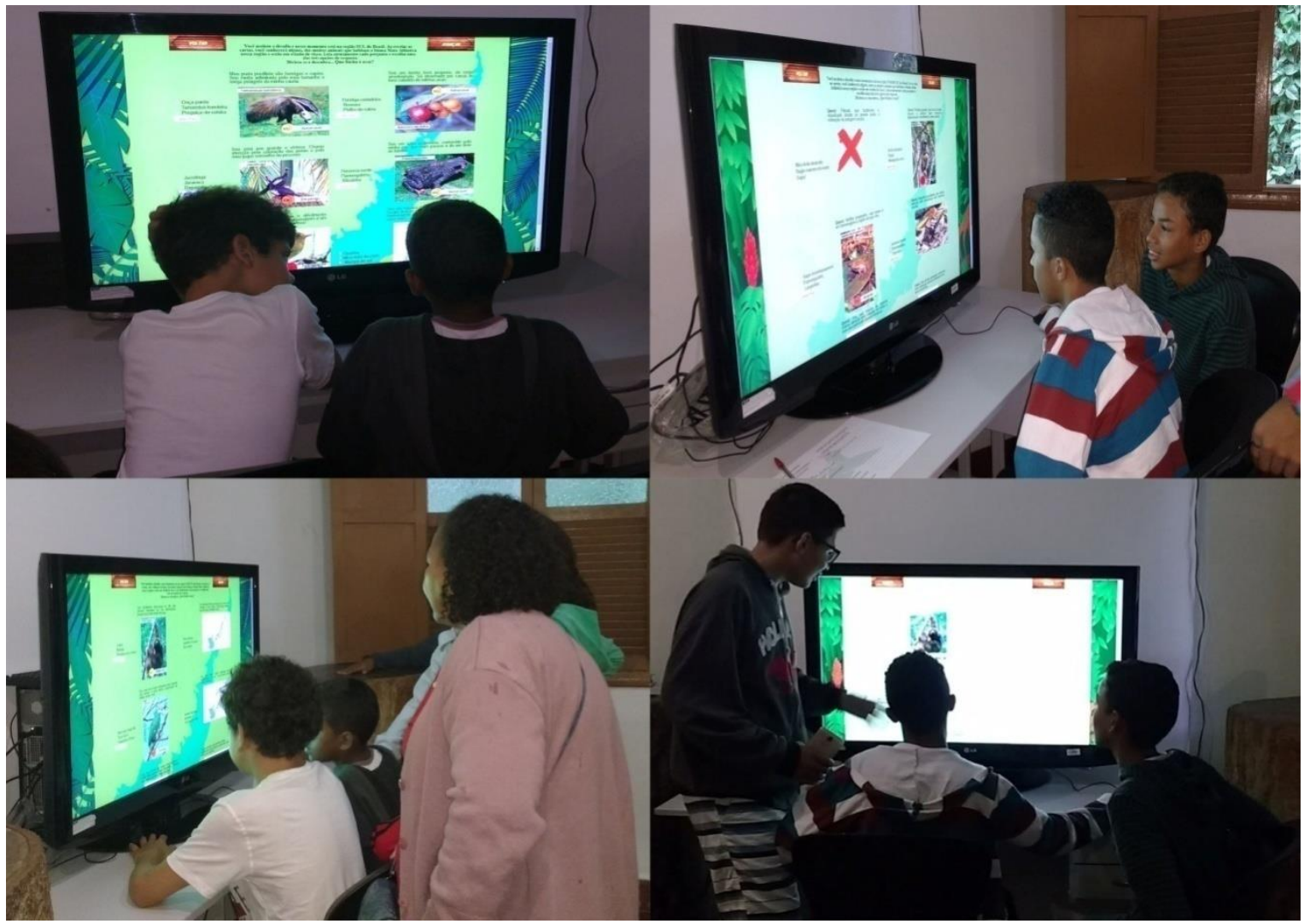

Fonte: Autor. 
Figura 6 - Distribuição de visitantes no Museu de Biologia Professor Mello Leitão por município e estado, durante o período de exposição e avaliação do álbum de figurinhas online Por dentro da Mata Atlântica.

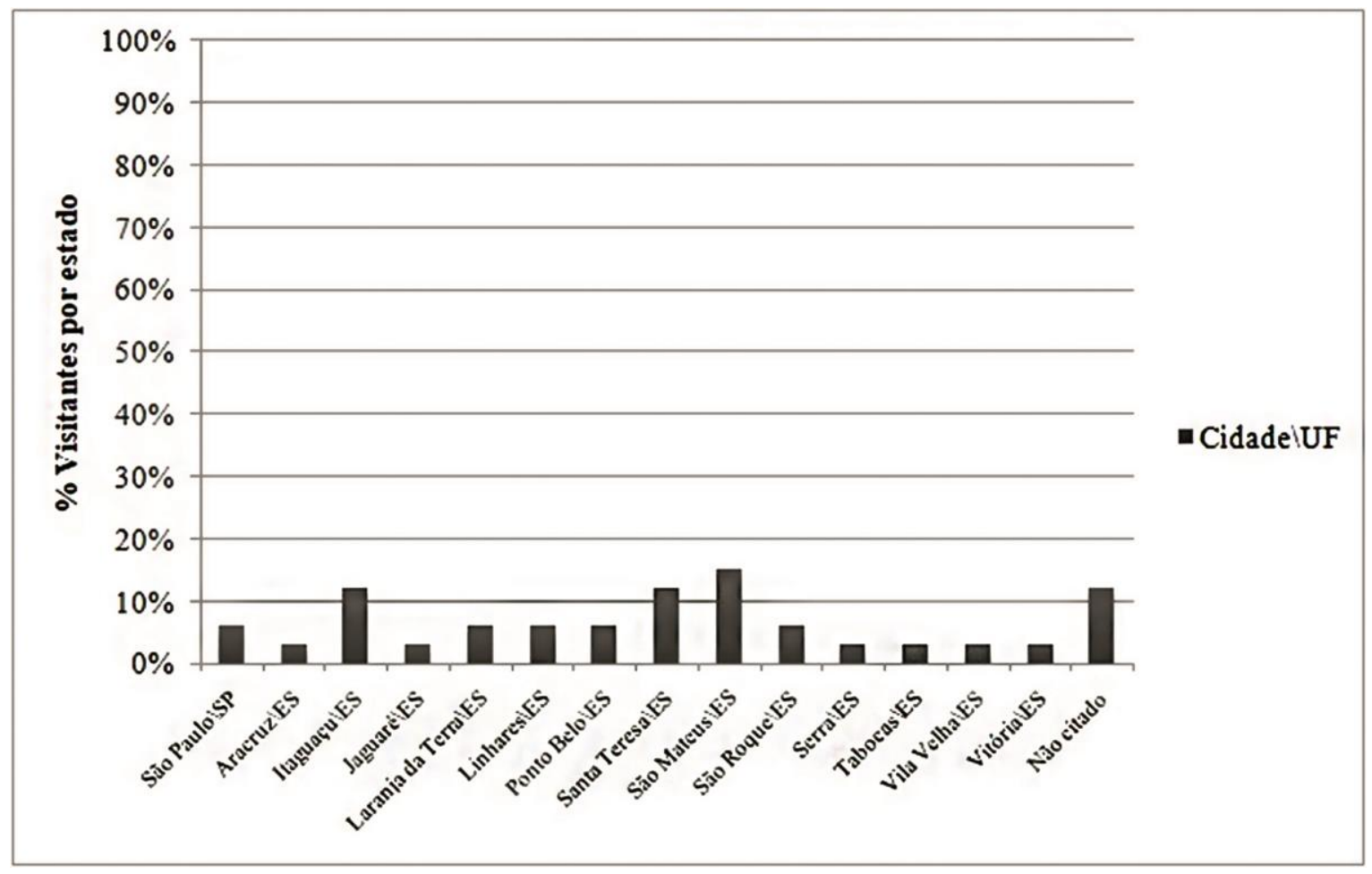

Fonte: Autor. Elaborada a partir de dados de pesquisa.

\section{Tabelas}

Tabela 1 - Lista das espécies de fauna e flora habitantes e endêmicas da Mata Atlântica, inseridas nas versões online e impressa do álbum Por dentro da Mata Atlântica, segundo as listas de espécies ameaçadas, considerando a presença e distribuição na localidade (UF) e estado de conservação.

\section{Categoria taxonômica}

\section{Vertebrados terrestres}

Aburria jacutinga (Spix, 1825)*

Adelophryne maranguapensis (Hoogmoed, Borges \& Cascon, 1994)

Alouatta guariba guariba (Humboldt, 1812) *

Amazona rhodocorytha (Salvadori, 1890)

Bothrops pirajai Amaral, 1923

Brachyteles arachnoids Geof froy, 1806 *

Brachyteles hypoxanthus (Kuhl, 1820)*

Bradypus torquatus**

Callithrix aurita (Geoffroy in Humboldt, 1812) **
Localidade (UF)

Estado de conservação 
Chaetomys subspinosus* (Olfers, 1818)

Hemitriccus kaempferi (Zimmer, 1953)

Leopardus pardalis mitis (Cuvier, 1820)

Melanophryniscus dorsalis (Mertens, 1933)

Myrmecophaga tridactyla Linnaeus, 1758.

Priodontes maximus (Kerr, 1792)

Puma concolor capricornensis Goldman, 1946

Speothos venaticus (Lund, 1842)

Thalurania watertonii (Bourcier, 1847)**

Xipholena atropurpurea (Wied, 1820) *
$B A, E S, M G, R J, S E$

PR

CR

$A L, B A, C E, E S, M G, S P, R J$,

MS, MT, RS, PR, SC, PB, PE

VU

RS, SC

VU

$M G, P R, R S, S P$

VU

ES, MG

VU

ES, MG, MS, PR, RJ, RS, SC, $\mathrm{SP}$

VU

$A L, B A, C E, E S, M G, M T, P B$,

$P E, P R, R S, S C, S P$

VU

$A L, B A, P E, S E$

VU

$A L, B A, E S, P B, P E, R J, S E$

EN

\section{Vertebrados aquáticos}

Gymnogeophagus setequedas Reis,

Malabarba \& Pavanelli, 1992

PR

VU

Elacatinus figaro Sazima, Moura \& Rosa, 1997

$B A, E S, P B, P E, R J, R N, S C, S P$

EN

\section{Invertebrados terrestres}

Actinote zikani D 'Almeida, 1951

$R J, S P$

$\mathrm{CR}$

Dichotomius schiffleri Vaz-de-Mello, Louzada \& Gavino, 2001

ES

Doryphora reticulata (Fabricius, 1787)

RS, SC

VU

Dynastes hercules Paschoali Grossi \& Arnaud,

1991.

$B A, E S, R J$

Pampasatyrus gyrtone (Berg, 1877)

MG, RJ, SC, SP

EN

Megasoma gyas gyas (Herbst, 1785)

$B A, E S, M G, R J, S P$

VU

\section{Florestais}

Apuleia leiocarpa (Vogel) J.F.Macbr.

$A L, B A, C E, E S, M G, M T, P A$,

$P B, P E, P R, R J, R N, R S, S C, S E$

VU

Araucaria angustifolia (Bertol.) Kuntze

$\mathrm{PR}, \mathrm{RS}, \mathrm{SC}$

EN

Caesalpinia echinata Lam.

$A L, B A, E S, P B, P E, R J, R N$

EN

$A L, B A, E S, M G, M T, M S, P A$,

Cedrela fissilis Vell.

$P E, R J, R N, R S, S C, S P$

VU

$A L, B A, E S, M G, R J, P A, P B$,

$P E, R S, S E, S C, S P$

VU 
Fonte: Autor. Elaborada a partir de dados da pesquisa no Livro Vermelho da Fauna Brasileira Ameaçada de Extinção (2008); Fundação Biodiversitas (2003); e Livro Vermelho CNCFLORA (2012.2). * Espécie endêmica da Mata Atlântica. ** Espécie endêmica da Mata Atlântica e na região.

Tabela 2 - Caracterização do perfil de visitantes e jogadores do álbum de figurinhas online Por dentro da Mata Atlântica com base na avaliação de perguntas referente à origem, idade, hábito de visitação a museus e distribuição de acordo com a frequência.

\begin{tabular}{|c|c|c|c|c|c|c|c|c|c|c|c|}
\hline \multirow[t]{2}{*}{ Perfil } & \multicolumn{2}{|c|}{ Total } & \multirow[t]{2}{*}{$\begin{array}{l}\text { Idade } \\
\text { (anos) }\end{array}$} & \multicolumn{2}{|c|}{$\begin{array}{c}\text { MC/HN } \\
(\operatorname{sim})\end{array}$} & \multicolumn{2}{|c|}{$\begin{array}{c}\text { MC/HN } \\
\text { (não) }\end{array}$} & \multicolumn{2}{|c|}{$\begin{array}{c}\text { MBML/ } \\
\text { INMA } \\
\text { (sim) }\end{array}$} & \multicolumn{2}{|c|}{$\begin{array}{c}\text { MBML/ } \\
\text { INMA } \\
\text { (não) }\end{array}$} \\
\hline & $\mathbf{n}$ & $\%$ & & $\mathbf{n}$ & $\%$ & $\mathbf{n}$ & $\%$ & $\mathbf{n}$ & $\%$ & $\mathbf{n}$ & $\%$ \\
\hline Aluno & 22 & 66,7 & $8-17$ & 10 & 30,3 & 12 & 36,4 & 7 & 21,2 & 15 & 45,5 \\
\hline Professor & 3 & 9,1 & $33-37$ & 3 & 9,1 & 0 & 0,0 & 3 & 9,1 & 0 & 0,0 \\
\hline Visita Espontânea & 8 & 24,2 & $9-48$ & 4 & 12,1 & 4 & 12,1 & 6 & 18,2 & 2 & 6,1 \\
\hline Total & 33 & 100 & & $\begin{array}{l}1 \\
7\end{array}$ & 51,5 & 16 & 48,5 & 16 & 48,5 & 17 & 51,5 \\
\hline
\end{tabular}

Fonte: Autores. Elaborada a partir de dados de pesquisa. MC/HN (Museu de Ciências/História Natural); MBML (Museu de Biologia Professor Mello Leitão/Instituto Nacional da Mata Atlântica).

\begin{tabular}{lccccccc}
\hline \multicolumn{7}{c}{ Expectativa de visita (\%) } \\
\hline Perfil & Animais & $\begin{array}{c}\text { Vegetai } \\
\text { s }\end{array}$ & Expo. & Jogos & Fotos & Brin. & Cont. Histo. \\
\hline Aluno & 9,1 & 6,1 & 6,1 & 3,0 & 6,1 & 3,0 & 6,1 \\
Professor & 21,2 & 9,1 & 15,2 & 3,0 & 9,1 & 3,0 & 9,1 \\
Visita Espontânea & 51,5 & 18,2 & 18,2 & 3,0 & 18,2 & 3,0 & 15,2 \\
\hline Total & $\mathbf{8 1 , 8}$ & $\mathbf{3 3 , 4}$ & $\mathbf{3 9 , 5}$ & $\mathbf{9 , 0}$ & $\mathbf{3 3 , 4}$ & $\mathbf{9 , 0}$ & $\mathbf{3 0 , 4}$ \\
\hline
\end{tabular}

Fonte: Autores. Elaborada a partir de dados de pesquisa. Expo. (Exposições); Brin. (Brincadeiras); Cont. Hist. (Conteúdo Histórico). 


\begin{tabular}{lccccccccc}
\hline & \multicolumn{1}{c}{ Questões (\%) } \\
\hline Alternativa & Q1 & Q2 & Q3 & Q4 & Q5 & Q6 & Q7 & Q8 & Q9 \\
\hline Concordo & 81,8 & 63,6 & 69,7 & 75,8 & 54,5 & 100 & 95,5 & 69,7 & 66,7 \\
Concordo parcialmente & 9,1 & 21,2 & 15,2 & 18,2 & 27,3 & 0 & 0 & 9,1 & 12,1 \\
Indiferente & 0 & 0 & 6,1 & 3,0 & 6,1 & 0 & 4,5 & 12,1 & 12,1 \\
Discordo & 9,1 & 15,2 & 9,1 & 3,0 & 12,1 & 0 & 0 & 9,1 & 3,0 \\
Não respondeu & & & & & & & & & 6,1 \\
\hline
\end{tabular}

Fonte: Autor. Elaborada a partir de dados de pesquisa.

\section{Agradecimentos}

Agradecemos ao Ministério da Ciência, Tecnologia, Inovações e Comunicações - MCTIC e ao Conselho Nacional de Desenvolvimento e Pesquisa - CNPq pelo apoio financeiro ao projeto de pesquisa de Fortalecimento Científico do Instituto Nacional da Mata Atlântica, através do edital no 454789/2015-7 e bolsas de pesquisa concedidas ao primeiro e ao terceiro autor (processos n0301079/2017-0 e no 312927/2016-9, respectivamente).

\section{Referências}

ALMEIDA, A.M. Desafios da Relação Museu-Escola. Comunicação \& Educação, São Paulo, n. 10, p. 50-56, 1997.

ANGÉLICO, J.N.L. Os Jogos Online nos Serviços Educativos de Museus: um estudo para o Museu Regional de Arqueologia D. Diogo de Sousa. 2010. Dissertação (mestrado) - Faculdade de Engenharia da Universidade do Porto, Porto, 2010, PT-P.

BERTOLETTI-DE-MARCHI, A.C.; da SILVA, F.B. O Desenvolvimento de Objetos de Aprendizagem no Museu Zoobotânico Augusto Ruschi. Revista Novas Tecnologias na Educação, Passo Fundo, v. 2, n. 2, p. 1-9, 2004.

BRASIL. Ministério da Educação e do Desporto. Secretaria de Educação Fundamental. Parâmetros Curriculares Nacionais: ciências naturais. Brasília: MEC/SEF, v. 4, 1997. 136 p.

Ministério da Educação e do Desporto. Secretaria de Educação Fundamental. Parâmetros Curriculares Nacionais: Meio Ambiente e Saúde. Brasília: MEC/SEF, v. 9, 1997. 128 p.

CHIARELlO, A.G.; AGUIAR, L.M.S.; CERQUEIRA, R. (Ed.) Mamíferos. In: MACHADO, A.B.M.; DRUMMOND, G.M.; PAGLIA, A.P. Livro Vermelho da Fauna Brasileira Ameaçada de Extinção. Brasília: DF, v. 2, p. 690$697,2008$.

CNCFLORA. Centro Nacional de Conservação da Flora. Lista Vermelha da Flora Brasileira versão 2012.2. Disponível na URL: http://cncflora.jbrj.gov.br/portal/pt-br/listavermelha. Acesso em: 15 ago. 2017.

CURY, M.X. Educação em Museus: panorama, dilemas e algumas ponderações. Ensino Em Re-Vista, Uberlândia, v.20, n.1, p.13-28, 2013.

FRANKE, C.R.; ROCHA, P.L.B. da; KLEIN, W.; GOMES, S.L (orgs.). Mata Atlântica e Biodiversidade. Salvador: Edufba, 2005. 461 p.

FUNDAÇÃO BIODIVERISTAS. Lista das Espécies Ameaçadas da Fauna Brasileira 2003. Disponível na URL: http://www.biodiversitas.org.br/f_ameaca/consulta.asp. Acesso em: 21 jul. 2017. 
FUNDAÇÃO SOS MATA ATLÂNTICA; INSTITUTO NACIONAL DE PESQUISAS ESPACIAIS. Atlas dos Remanescentes Florestais da Mata Atlântica período 2015-2016: relatório técnico. São Paulo, 2017. 69 p.

GROS, B. Digital Games in Education. Journal of Research on Technology in Education, United Kingdom, v. 40, n. 1, p. 23-38, 2007.

GRÜBEL, J.M.; BEZ, M.R. Jogos Educativos. Revista Novas Tecnologias na Educação, Porto Alegre, v. 4, n. 2, p.1-7, 2006.

HADDAD, C.F.B. Anfíbios. In: MACHADO, A.B.M.; DRUMMOND, G.M.; PAGLIA, A.P. Livro Vermelho da Fauna Brasileira Ameaçada de Extinção. Brasília: DF, v. 2, p. 291, 2008.

ICMBIO. Instituto Chico Mendes de Conservação da Biodiversidade. Livro Vermelho da Fauna Brasileira Ameaçada de Extinção: sumário executivo. Brasília: DF, v. 9, 2016.

LARA, I.C.M. de. O Jogo como Estratégia de Ensino de $5^{a}$ a $8^{a}$ serie. In VIII Encontro de Educação em Matemática, p. 1-10. Anais. Recife, 2004. Disponível na URL: http://www.sbembrasil.org.br/files/viii/pdf/02/MC63912198004.pdf. Acesso em: 26 jan. 2018.

MACHADO, A.B.M.; BRESCOVIT, A.D.; MIELKE, O.H. (Ed.). Invertebrados terrestres. In: MACHADO, A.B.M.; DRUMMOND, G.M.; PAGLIA, A.P. Livro Vermelho da Fauna Brasileira Ameaçada de Extinção. Brasília: DF, v. 2, p. 304-306, 2008.

MARTINS, M.; MOLINA, F.B. Répteis. In: MACHADO, A.B.M.; DRUMMOND, G.M.; PAGLIA, A.P. Livro Vermelho da Fauna Brasileira Ameaçada de Extinção, Brasília: DF, v. 2, p. 332-333, 2008.

MESSEDER NETO, H.S.; MORADILLO, E.F. O jogo no ensino de química e a mobilização da atenção e da emoção na apropriação do conteúdo científico: aportes da psicologia histórico-cultural. Ciência \& Educação, Bauru, v. 23, n. 2, p. 523-540, 2017.

NASCIMENTO, G.C.C. O conhecimento local e suas contribuições para a conservação. Revista Educação Ambiental em Ação, n. 59, 2017. Disponível na URL: http://www.revistaea.org/pf.php?idartigo=2659. Acesso em: 08 mai. 2017.

PAULA, B.H.; VALENTE, J.A. Jogos digitais e educação: uma possibilidade de mudança da abordagem pedagógica no ensino formal. Revista Ibero-americana de Educação, Araraquara, v. 70, n. 1, p. 9-28, 2016.

ROSA, R.S.; LIMA, F.C.T. Peixes. In: MACHADO, A.B.M.; DRUMMOND, G.M.; PAGLIA, A.P. Livro vermelho da fauna brasileira ameaçada de extinção. Brasília: DF, v. 2, p. 17, 2008.

SANTANA, F.R.; NOGUEIRA-FERREIRA, F.H. O Museu de Biodiversidade do Cerrado e sua ação educativa. Em extensão, Uberlândia, v. 8, n. 2, p. 11-22, 2009.

SAVI, R.; ULBRICH, V.R. Jogos digitais educacionais: benefícios e desafios. Revista Novas Tecnologias na Educação, Passo Fundo, v.6, n. 2, p.1-10, 2008.

SILVA, L.R. Videojogos: Usos Sociais em diferentes gerações de jogadores. 2014. Dissertação (mestrado) Programa de Pós-Graduação Stricto Sensu em Cominicação, Universidade Católica de Brasília, 2014, Brasília, BR-DF.

SILVEIRA, L. F.; STRAUBE, F. C. Aves. In: MACHADO, A.B.M.; DRUMMOND, G.M.; PAGLIA, A.P. Livro vermelho da fauna brasileira ameaçada de extinção. Brasília: DF, v. 2, p. 384-644, 2008.

TABARELli, M.; PINTO, L. P.; SILVA, J. M. C.; HIROTA, M. M.; BEDÊ, L. C. Desafios e oportunidades para a conservação da biodiversidade na Mata Atlântica brasileira. Megadiversidade, v. 1, n. 1, p. 132-138, 2005.

TOALDO, A. M.; MEYNE, L. S. A educação ambiental como instrumento para a concretização do desenvolvimento sustentável. Revista Eletrônica do Curso de Direito da UFSM, v. 8, p. 661-673, 2013.

VIEIRA, S. Como elaborar questionários. São Paulo: SP, 2009. 160 p. 
Recebido em fevereiro de 2019

Aprovado para publicação em abril de 2019

\section{Arlindo Serpa Filho}

Pós-Doutorado no Instituto Nacional da Mata Atlântica (INMA). Doutor em Entomologia pelo Instituto Nacional de Pesquisas da Amazônia (INPA). Mestre em Biologia Parasitária pela Fundação Oswaldo Cruz (FIOCRUZ). Licenciado em Ciências pela Federação das Faculdades Celso Lisboa.

serpafilhoa5@gmail.com

\section{Everton Messias Santos Sena}

Especialização em andamento em Educação e Contemporaneidade pelo Instituto Federal do Espírito Santo. Graduado em Analise e Desenvolvimento de Sistemas pelo Instituto Federal do Espírito Santo.

alunomessias@gmail.com

\section{Mônica Salazar Souza}

Doutoranda em Ciências e Biotecnologia pela Universidade Federal Fluminense (UFF). Mestra em Ciências Biológicas (Biodiversidade Neotropical) pela Universidade Federal do Estado do Rio de Janeiro (UNIRIO). Licenciada em Ciências Biológicas pelo Centro Universitário Celso Lisboa (UCL). Graduada em Gestão da Tecnologia da Informação pela Universidade Estácio de Sá (UNESA). Foi Pesquisadora-Bolsista no Instituto Nacional da Mata Atlântica (INMA), atuando no Projeto de Fortalecimento Científico do Instituto Nacional da Mata Atlântica - $2^{\circ}$ biênio entre 2017/2018.

mosalazars@gmail.com 